\title{
A preliminary study to assess the construct validity of a cultural intelligence measure on a South African sample
}

\author{
Authors: \\ Bright Mahembe ${ }^{1,2}$ \\ Amos S. Engelbrecht ${ }^{1}$ \\ Affiliations: \\ ${ }^{1}$ Department of Industrial \\ Psychology, Stellenbosch \\ University, South Africa \\ ${ }^{2}$ School of Economic and \\ Business Sciences, University \\ of the Witwatersrand, \\ South Africa \\ Correspondence to: \\ Bright Mahembe \\ Email: \\ bmahembe@sun.ac.za \\ Postal address: \\ Private Bag X1, Matieland \\ 7602, South Africa \\ Dates: \\ Received: 10 June 2013 \\ Accepted: 05 June 2014 \\ Published: 04 Sept. 2014 \\ How to cite this article: \\ Mahembe, B., \& Engelbrecht, \\ A.S. (2014). A preliminary \\ study to assess the construct \\ validity of a cultural \\ intelligence measure on a \\ South African sample. SA \\ Journal of Human Resource \\ Management/SA Tydskrif vir \\ Menslike Hulpbronbestuur, \\ 12(1), Art. \#558, 8 pages. \\ http://dx.doi.org/10.4102/ \\ sajhrm.v12i1.558
}

\section{Copyright:}

(C) 2014. The Authors.

Licensee: AOSIS

OpenJournals. This work

is licensed under the

Creative Commons

Attribution License.
Read online:
Orientation: Cultural intelligence is an essential social competence for effective individual interaction in a cross-cultural context. The cultural intelligence scale (CQS) is used extensively for assessing cultural intelligence; nevertheless, its reliability and validity on a South African sample are yet to be ascertained.

Research purpose: The purpose of the current study was to assess the construct validity of the CQS on a South African sample. The results of the psychometric assessment offer some important insights into the factor structure of the cultural intelligence construct.

Motivation for the study: The current study sought to provide some practical validity confirmation of the CQS for the effective management of cultural diversity in the South African context.

Research approach, design and method: The CQS was administered on a non-probability sample of 229 young adults in South Africa. Item analysis was performed to ascertain reliability. Exploratory factor analysis was used to test the unidimensionality of CQS subscales. The first-order and second-order factor structures underlying contemporary models of cultural intelligence were tested using confirmatory factor analysis.

Main findings: Results indicated that the CQS is a reliable and valid measure of cultural intelligence as evidenced by the high internal consistency coefficients in all the subscales. Good construct validity for both the first-order and second-order models was obtained via confirmatory factor analysis.

Practical/managerial implications: The study finds good measurement properties of the CQS in a South African context. The CQS can be confidently used for applications such as selecting, training and developing a more culturally competent workforce.

Contribution: The study extends the body of knowledge on the reliability and construct validity of the CQS in the South African milieu. It further indicates that cultural intelligence can be represented by a general cultural intelligence factor that drives more specific dimensions of cultural intelligence.

\section{Introduction}

\section{Key focus of the study}

Cultural intelligence is a specific form of intelligence that emphasises an individual's capability to grasp, reason and behave effectively in situations characterised by cultural diversity (Ang et al., 2007; Schmidt \& Hunter, 2000). It is mostly concerned with ways of enhancing effective social interactions amongst individuals from different cultures and backgrounds to avoid potential conflict that can impact on organisational performance. Embracing individual differences makes cultural intelligence an extremely important social competence in the 'globalised' 21st-century workplace (Groves \& Feyerherm, 2011). Thus, cultural intelligence is a multifaceted construct targeted at situations involving cross-cultural interaction arising from, but not limited to, differences in race, ethnicity and nationality.

Cultural intelligence has been linked to positive outcomes such as better adjustment in diverse cultural situations which, in turn, increase the individual's effectiveness at the workplace (Van Dyne \& Ang, 2005). It fosters effective communication within the work environment, inspires good cultural judgement, cultural adaptation, the enactment of sound decision-making and task performance (Ang et al., 2007). It is one of the key tenets of successful transformational leaders (Ismail, Reza \& Mahdi, 2012). Elenkov and Manev (2009) report that cultural intelligence moderates the positive relationship between visionary-transformational leadership and organisational innovation, such that leaders with higher cultural intelligence magnify the positive effect of leadership on innovation. Furthermore, the leader's cultural intelligence 
is strongly related to leader and team performance (Groves \& Feyerherm, 2011) as well as to leader emergence (Rockstuhl, Ang, Ng, Van Dyne \& Lievens, 2009).

Cultural intelligence has also been reported to have a negative relationship with emotional exhaustion (Tay, Rossi \& Westman, 2010), an important psychological outcome given the increased demands on employees in a diverse workplace. In addition, cultural intelligence has been found to increase affect-based trust amongst culturally diverse members of multicultural professional networks (Chua \& Morris, 2009). Imai and Gelfand (2010) report that negotiators with higher cultural intelligence demonstrate more integrative information behaviours and cooperative relationship management behaviours in the context of intercultural negotiation. Cultural intelligence predicts the development of social networks after controlling for international experience, host country language fluency and cultural distance (Fehr \& Kuo, 2008). Overall, observed evidence demonstrates that cultural intelligence is crucial for important work outcomes of culturally diverse organisations.

\section{Research purpose}

Despite the relevance of cultural intelligence for embracing individual differences at work and fostering success in intercultural negotiations, research on its measurement is relatively sparse. The only widely used cultural intelligence measure to date is the cultural intelligence scale (CQS) developed by Ang et al. (2007). The measure was developed and validated in the USA, Singapore and Iran and is still being validated for use in various cultural settings (Ang et al., 2007; Khodadady \& Ghahari, 2011). It is also important to evaluate the psychometric properties of the CQS on a South African sample.

\section{Objectives}

Since most of the studies on the measurement properties of the CQS were carried out in the USA and Singapore (for a review, see Ang et al., 2007), it was considered important to validate the CQS before its extensive use in South Africa. The primary research question of the current study was therefore: is the cultural intelligence scale a reliable and valid measure of cultural intelligence in the South African milieu? Stated differently, this study sought to test the reliability and construct validity of the CQS on a South African sample. A secondary aim of the study was to ascertain the fit of the first-order and second-order factor structure of cultural intelligence on a South African sample.

\section{Contribution to the field}

The present study sought to validate a measure of cultural intelligence in a South African setting as well as the applicability and appropriateness of the underlying cultural intelligence theoretical model (Mahembe, Engelbrecht \& De Kock, 2013). In addition to the potential to facilitate the effective interaction and performance of employees and managers at work, cultural intelligence could have wider socioeconomic relevance in developing countries such as South Africa. Cultural intelligence is a social competency (Fehr \& Kuo, 2008) that could facilitate the transformation and tolerance of diversity in South Africa (De Goede \& Theron, 2010; Kamps \& Engelbrecht, 2011). South Africa, in addition, is one of the countries experiencing the challenges of internal African immigration, perhaps receiving the largest number of foreign nationals in the world (United Nations High Commissioner for Refugees [UNHCR], 2010). In this respect, South Africa has become a centre of cultural confluence for people with different cultural backgrounds. Fostering cultural intelligence at various levels is a key aspect of affirming individuals, groups and society. The authors therefore foresee opportunities to utilise the CQS (if it would be able to measure cultural intelligence suitably in the local context) in applications in both work and non-work (e.g. community) settings, including the educational context to improve diversity management.

To summarise, the purpose of the present study is to test the CQS in the South African context in order to ascertain its psychometric properties. In the subsequent sections, we provide the theoretical background of the cultural intelligence construct followed by the method, the results and a discussion of the findings; we conclude with recommendations for practice and research.

\section{Literature review Cultural intelligence theory}

Cultural intelligence can be defined as 'a person's capability to adapt effectively to new cultural contexts' (Earley \& Ang, 2003, p. 59). Cultural intelligence comprises metacognitive, cognitive, motivational and behavioural cultural intelligence facets that positively influence interaction effectiveness in culturally diverse settings (Ang, Van Dyne \& Tan, 2011). Cultural intelligence theory draws from Sternberg and Detterman's (1986) framework, which proposes that intelligence has different 'loci' within the person: metacognition, cognition and mental capabilities located within the 'head' of the person as well as overt actions manifested in behavioural capabilities. It builds on the growing interest in 'real-world' non-academic intelligences that focus on specific content domains such as social intelligence (Thorndike \& Stein, 1937), emotional intelligence (Mayer \& Salovey, 1993) and practical intelligence (Sternberg \& Wagner, 2000) by focusing on a specific domain, namely intercultural settings. It is motivated by the practical reality of globalisation (Earley \& Ang, 2003).

According to cultural intelligence theory, the achievement of general cultural intelligence is a function of four primary cultural intelligence dimensions comprising metacognitive, cognitive, motivational and behavioural cultural intelligence (Earley \& Ang, 2003), which will be discussed next.

\section{Cultural intelligence dimensions}

Metacognitive cultural intelligence: Metacognitive cultural intelligence refers to an individual's level of conscious cultural 
awareness during cross-cultural interactions and involves higher-level cognitive strategies that enable individuals to develop heuristics and rules for social interaction in novel cultural environments (Ng, Van Dyne \& Ang, 2012). People with high metacognitive cultural intelligence assess their own cultural assumptions as well as reflect and adjust their cultural knowledge during a cross-cultural interaction (Ang et al., 2011). The higher-level cognitive strategies include planning, monitoring and revising mental models of cultural norms for people with different cultural backgrounds (Ng et al., 2012).

Cognitive cultural intelligence: Cognitive cultural intelligence reflects knowledge of the norms, practices and conventions in different cultures acquired from education and personal experiences ( $\mathrm{Ng}$ et al., 2012). It includes knowledge of the economic, legal, sociolinguistic and interpersonal systems of different cultures and subcultures (Triandis, 2006) and knowledge of basic cultural values, for example as in Hofstede's (2001) cultural framework. Individuals with high cognitive cultural intelligence are expected to have an understanding of similarities and differences across cultures (Brislin, Worthley \& MacNab, 2006).

Motivational cultural intelligence: Motivational cultural intelligence reflects the drive towards learning about and functioning in diverse contexts ( $\mathrm{Ng}$ et al., 2012). It indicates an individual's intrinsic interest in understanding and experiencing how the cultures of others are manifested. In cross-cultural situations, individuals with high motivational cultural intelligence direct attention and energy chiefly out of intrinsic interest (Deci \& Ryan, 1985) and high confidence in their cross-cultural effectiveness.

Behavioural cultural intelligence: Behavioural cultural intelligence demonstrates the capability to engage in appropriate verbal and non-verbal actions in a crosscultural context ( $\mathrm{Ng}$ et al., 2012). Behavioural cultural intelligence complements the mental capabilities spelt out in the metacognitive and cognitive cultural intelligences, as well as the motivation manifested in motivational cultural intelligence. Individuals with high behavioural cultural intelligence exhibit situationally appropriate behaviours based on their broad range of verbal and non-verbal capabilities, such as culturally appropriate words, tones, gestures and facial expressions (Gudykunst, Ting-Toomey \& Chua, 1988).

\section{Measurement of cultural intelligence}

Despite the existence of research findings that cultural intelligence is an essential prerequisite for effective social functioning in a cross-cultural context, its potential contribution is subject to the availability of a reliable and valid measure of the construct (Ang et al., 2007). To date, there is only one recent and widely used cultural intelligence measure, namely the CQS (Ang et al., 2007). The 20-item CQS was developed by Ang et al. (2007) from an initial pool of 53 items with approximately 13 items assessing each of the four cultural intelligence dimensions discussed above. A panel of subject matter experts reviewed the items for clarity, readability and definitional fidelity and retained 10 items for each dimension. The 40-item scale was administered in Singaporean samples and the authors eventually deleted items with small standard deviations, extreme means, low item-to-total correlations, high residuals and low factor loadings, resulting in the current 20 -item scale. The 20 -item scale comprises four items measuring metacognitive cultural intelligence, six items for cognitive cultural intelligence, five items for motivational cultural intelligence and five items for behavioural cultural intelligence. Confirmatory factor analysis demonstrated good fit of the four-factor model to the data (goodness-of-fit $=0.92$, non-normed fit index $=0.96$, comparative fit index $=0.97$, standardised root mean square residual $=0.046$ and root mean square error of approximation $=0.053)($ Ang, Van Dyne \& Koh, 2006). The CQS has been validated in the USA and Singapore (Ng et al., 2012). Acceptable reliability of the four underlying subscales (0.72-0.86) and factor stability have been confirmed on the USA and Singaporean samples.

\section{The present study}

The present study attempted to ascertain the reliability and construct validity of the CQS on a South African sample. The authors also wanted to determine whether or not a secondorder model would also fit the data in addition to a firstorder model.

\section{Method \\ Research approach}

A quantitative survey design was required in order to conduct confirmatory factor analysis via structural equation modelling. Common source bias was not considered a threat in the current study, as the authors measured only a single latent cultural intelligence construct and its manifest variables.

\section{Research participants}

By using a non-probability sampling strategy, the study used students studying full time at a South African university. The study initially used an electronic survey method. However, due to a poor response rate, the authors decided to administer 400 hard-copy questionnaires to participants; 229 completed questionnaires were returned. The hard-copy questionnaires were administered in class, with voluntary participation. This sample consisted of 156 female (68.1\%) and 73 male (31.9\%) respondents. The majority (55.5\%) were under 20 years of age. The ethnic distribution in the sample was white $(70.7 \%)$, mixed race $(16.2 \%)$; black $(10 \%)$ and Indian $(3.1 \%)$. The majority $(66.7 \%)$ of respondents had a matriculation qualification as the highest level of education.

\section{Measuring instrument: Cultural intelligence scale}

Cultural intelligence was measured using the CQS (Ang et al., 2007). The CQS contains 20 item statements 
assessed using a seven-point Likert intensity scale ranging from 1 (strongly disagree) to 7 (strongly agree). The CQS items comprise four subscales: metacognitive, cognitive, motivational and behavioural cultural intelligence subscales. These subscales are discussed below.

Metacognitive cultural intelligence: Metacognitive cultural intelligence was measured by four items. Example items are:

- 'I am conscious of the cultural knowledge I use when interacting with people with different cultural backgrounds.'

- 'I check the accuracy of my cultural knowledge as I interact with people from different cultures.'

Cognitive cultural intelligence: Cognitive cultural intelligence was measured by six items. Example items are:

- 'I know the legal and economic systems of other cultures.'

- 'I know the rules for expressing nonverbal behaviours in other cultures.'

Motivational cultural intelligence: Motivational cultural intelligence was measured by five items. Example items are:

- 'I enjoy interacting with people from different cultures.'

- 'I enjoy living in cultures that are unfamiliar to me.'

Behavioural cultural intelligence: Behavioural cultural intelligence was measured by five items. Example items are:

- 'I change my verbal behaviour (e.g. accent, tone) when a cross-cultural interaction requires it.'

- 'I change my non-verbal behaviour when a cross-cultural situation requires it.'

Previous studies have shown generally acceptable reliability coefficients of the four underlying subscales ranging from 0.89 to 0.92 (Imai \& Gelfand, 2010).

\section{Research procedure}

Ethical and institutional permission for the study was obtained from the participating institution's research ethics committee. The ethical guidelines spelt out the aim of the study and participants' rights. Informed consent was required from the participants before completion of the questionnaires. Confidentiality of the data obtained was assured. No potential risks to participants were envisaged in the study.

\section{Statistical analysis}

The confirmatory factor analysis procedure available in LISREL 8.80 was used to test the first-order and second- order factor structure of the CQS. According to Hair, Black, Babin and Anderson (2010), confirmatory factor analysis, a structural modelling technique, provides one of the best multivariate procedures for ascertaining construct validity amongst constructs defined by several manifest variables. The robust maximum likelihood estimation was used to address the lack of multivariate normality in the data (Jöreskog \& Sörbom, 1996; Mels, 2003).

\section{Results}

\section{Preliminary analysis \\ Missing values}

The missing values problem was addressed using the multiple imputation method. The main advantage of the multiple imputation method is that estimates of missing values are derived for all cases in the initial sample and no cases with missing values are deleted (Du Toit \& Du Toit, 2001; Mels, 2010). The utilisation of the multiple imputation method culminated in a total sample size of 229 cases (Jöreskog \& Sörbom, 1996).

\section{Item analysis}

The SPSS software reliability procedure was used to perform item analysis on the items of the CQS. The coefficient alpha values of all the subscales were high $(\alpha>0.80)$, except for one subscale (metacognitive cultural intelligence), which was marginally below the 0.80 level (see Table 1) (Nunnally, 1978).

\section{Dimensionality analysis}

A principal axis factor analysis via direct oblimin rotation procedure was conducted to confirm the unidimensionality of each of the four CQS subscales before performing confirmatory factor analysis (Williams, Vandenberg \& Edwards, 2009). The number of factors to extract was determined by the 'eigenvalue greater than 1 ' guideline (Tabachnick \& Fidell, 2001). Unidimensionality was confirmed for each of the four subscales of the CQS. The resultant factor loadings for each of the four subscales were acceptable $(>0.30)$ and variance explained in each factor was satisfactory (> 40\%) (Tabachnick \& Fidell, 2001). The factor loadings are depicted in Table 3. It must be emphasised that exploratory factor analysis was only conducted to determine the unidimensionality of each scale and not to explore the factor structure of the CQS (Hair et al., 2010).

\section{Confirmatory factor analysis results First-order confirmatory factor analysis}

In the first-order measurement model, the four subscales were postulated to represent the cultural intelligence latent factors

TABLE 1: Reliability analysis, scale mean and standard deviation output for the cultural intelligence scale dimensions.

\begin{tabular}{|c|c|c|c|c|c|}
\hline Scale & Number of items & Cronbach's alpha & Corrected item-total correlations & Scale mean & Scale standard deviation \\
\hline Metacognitive cultural intelligence & 4 & 0.79 & $0.52-0.66$ & 14.70 & 2.59 \\
\hline Cognitive cultural intelligence & 6 & 0.81 & $0.45-0.68$ & 17.32 & 4.06 \\
\hline Motivational cultural intelligence & 5 & 0.83 & $0.56-0.65$ & 18.50 & 3.49 \\
\hline Behavioural cultural intelligence & 5 & 0.84 & $0.59-0.71$ & 16.75 & 3.87 \\
\hline
\end{tabular}


that explain the variance in their respective indicator variables. The root mean square error of approximation (RMSEA) of 0.046 (see Table 2) indicated good fit (Diamantopoulos \& Siguaw, 2000; Hair et al., 2010). The $p$-value for test of close fit (RMSEA < 0.05 ) of 0.714 demonstrates that the CQS first-order measurement model shows close fit. The absolute, relative and comparative indices all pointed towards acceptable model fit: goodness-of-fit $(\mathrm{GFI})=0.89$, non-normed fit index $(\mathrm{NNFI})=0.98$; normed fit index $(\mathrm{NFI})=0.94$, comparative fit index $(\mathrm{CFI})=0.98$ (Diamantopoulos \& Siguaw, 2000; Hair et al., 2010).

The completely standardised factor loadings (see Table 3) were substantial and significant (>0.5) (Diamantopoulos \& Siguaw, 2000). This provides some support that all items were reasonable indicators of their respective latent factors.

The latent variable correlations amongst the four CQS dimensions (see Table 4) reflect the correlations corrected for the attenuating effect of (random and systematic) measurement error. The correlations are within reasonable limits $(0.27<\phi<0.58)$, as high values $(>0.9)$ may have pointed towards multicollinearity (Tabachnick \& Fidell, 2001).

\section{Second-order confirmatory factor analysis}

A second-order confirmatory factor analysis (CFA), where a single cultural intelligence latent factor was postulated to affect the four dimensions of cultural intelligence, was conducted (see Figure 1). The findings of the secondorder CFA demonstrated that the data fits the model well $($ RMSEA $=0.05)$ (see Table 2). The $p$-value for test of close fit (RMSEA $<0.05$ ) of 0.661 shows that the CQS secondorder measurement model indicates close fit. Although the value for the standardised root mean residual (SRMR) (0.06) marginally missed the 0.05 cut-off (Diamantopoulos \& Siguaw, 2000) indicative of good fit, the other goodness-of-fit indices (see Table 2) indicated good fit of the second-order model with the data $(\mathrm{GFI}=0.89, \mathrm{NFI}=0.93, \mathrm{CFI}=0.98)$. The resulting fit indices suggest that both the first-order and second-order models provide a credible representation of the cultural intelligence construct (Ang et al., 2007).

The unstandardised gamma matrix (see Table 5) is used to determine the significance of the estimated path coefficients $\left(\gamma_{i j}\right)$ expressing the level of the influence of the general cultural intelligence factor on the four latent cultural intelligence dimensions. In Table 5, the gamma parameters are significant if $p<0.05$ (Diamantopoulos \& Siguaw, 2000). From the results it seems that general cultural intelligence has a significant and positive effect on all of its sub-dimensions.

\section{Model modification indices (first-order model)}

Modification indices demonstrate the extent to which the chi-square fit statistic decreases when a currently fixed

TABLE 2: Goodness-of-fit indices obtained for the cultural intelligence scale measurement and structural models.

\begin{tabular}{lllllll}
\hline Model & RMSEA & $\boldsymbol{p}_{\text {close fit }}$ & SRMR & GFI & NNFI & NFI \\
\hline First-order CFA & 0.046 & 0.714 & 0.056 & 0.89 & 0.98 & 0.94 \\
Second-order CFA & 0.047 & 0.661 & 0.062 & 0.89 & 0.98 & 0.97 \\
\hline
\end{tabular}

CFA, confirmatory factor analysis; RMSEA, root mean square error of approximation; $p_{\text {close fit }} p$-value for test of close fit ( $\mathrm{H}_{0}$ : RMSEA $\left.<0.05\right)$; SRMR, standardised root mean residual; GFI, goodnessof-fit; NNFI, Non-normed fit index; $\mathrm{NFI}$, Normed fit index; $\mathrm{CFI}$, Comparative fit index.

TABLE 3: Factor loading estimates ${ }^{\dagger}$ for the cultural intelligence scale from confirmatory and exploratory factor analysis.

\begin{tabular}{|c|c|c|c|c|c|c|c|c|}
\hline Item*: & $\begin{array}{l}\text { Metacognitive } \\
\text { cultural } \\
\text { intelligence }\end{array}$ & $\begin{array}{l}\text { Exploratory } \\
\text { factor analysis } \\
\text { loading }\end{array}$ & $\begin{array}{l}\text { Cognitive cultural } \\
\text { intelligence }\end{array}$ & $\begin{array}{l}\text { Exploratory } \\
\text { factor analysis } \\
\text { loading }\end{array}$ & $\begin{array}{l}\text { Motivational } \\
\text { cultural } \\
\text { intelligence }\end{array}$ & $\begin{array}{l}\text { Exploratory } \\
\text { factor analysis } \\
\text { loading }\end{array}$ & $\begin{array}{l}\text { Behavioural } \\
\text { cultural } \\
\text { intelligence }\end{array}$ & $\begin{array}{l}\text { Exploratory } \\
\text { factor analysis } \\
\text { loading }\end{array}$ \\
\hline 1 & 0.74 & $(0.75)$ & - & - & - & - & - & - \\
\hline 2 & 0.72 & $(0.69)$ & - & - & - & - & - & - \\
\hline 3 & 0.74 & $(0.78)$ & - & - & - & - & - & - \\
\hline 4 & 0.64 & $(0.60)$ & - & - & - & - & - & - \\
\hline 5 & - & - & 0.51 & $(0.50)$ & - & - & - & - \\
\hline 7 & - & - & 0.68 & $(0.69)$ & - & - & - & - \\
\hline 8 & - & - & 0.78 & $(0.78)$ & - & - & - & - \\
\hline 9 & - & - & 0.63 & $(0.62)$ & - & - & - & - \\
\hline 10 & - & - & 0.69 & $(0.68)$ & - & - & - & - \\
\hline 11 & - & - & - & - & 0.74 & $(0.71)$ & - & - \\
\hline 12 & - & - & - & - & 0.75 & $(0.74)$ & - & - \\
\hline 13 & - & - & - & - & 0.63 & $(0.62)$ & - & - \\
\hline 15 & - & - & - & - & 0.68 & $(0.69)$ & - & - \\
\hline 16 & - & - & - & - & - & - & 0.65 & $(0.65)$ \\
\hline 17 & - & - & - & - & - & - & 0.71 & $(0.74)$ \\
\hline 18 & - & - & - & - & - & - & 0.76 & $(0.75)$ \\
\hline 19 & - & - & - & - & - & - & 0.82 & $(0.79)$ \\
\hline 20 & - & - & - & - & - & - & 0.67 & $(0.66)$ \\
\hline
\end{tabular}

Note: All factor loadings $>0.5$. Exploratory factor analysis loadings in brackets.

t. Factor loadings are completely standardised (lambda X); + Item numbers correspond to the order in Ang, S., Van Dyne, L., Koh, C., Ng, K.Y, Templer, K.J., Tay, C., \& Chandrasekar, N.A. (2007). Cultural intelligence: Its measurement and effects on cultural judgment and decision making, cultural adaptation and task performance. Management and Organization Review, 3(3), 335-371. $\mathrm{http}: / /$ dx.doi.org/10.1111/j.1740-8784.2007.00082.x 
TABLE 4: Inter-correlations between latent cultural intelligence scale dimensions, average variance extracted and shared variance estimates.

\begin{tabular}{|c|c|c|c|c|}
\hline Dimension & $\begin{array}{l}\text { Metacognitive cultural } \\
\text { intelligence }\end{array}$ & $\begin{array}{l}\text { Cognitive cultural } \\
\text { intelligence }\end{array}$ & $\begin{array}{l}\text { Motivational cultural } \\
\text { intelligence }\end{array}$ & $\begin{array}{l}\text { Behavioural cultural } \\
\text { intelligence }\end{array}$ \\
\hline Metacognitive cultural intelligence & 0.51 & 0.15 & 0.28 & 0.34 \\
\hline Cognitive cultural intelligence & 0.39 & 0.43 & 0.19 & 0.07 \\
\hline Motivational cultural intelligence & 0.53 & 0.44 & 0.49 & 0.10 \\
\hline Behavioural cultural intelligence & 0.58 & 0.27 & 0.32 & 0.52 \\
\hline
\end{tabular}

Note: Correlations are below the diagonal, squared correlations are above the diagonal and average variance extracted estimates are presented on the diagonal.

$N=229$.

TABLE 5: Dimension intercorrelations between second-order cultural intelligence and first-order factors (unstandardised gamma matrix).

\begin{tabular}{llll}
\hline Factor & $\gamma$ & SE & $\boldsymbol{t}$ \\
\hline Metacognitive cultural intelligence & 0.88 & 0.10 & 8.56 \\
Cognitive cultural intelligence & 0.50 & 0.13 & 3.88 \\
Motivational cultural intelligence & 0.62 & 0.09 & 6.81 \\
Behavioural cultural intelligence & 0.62 & 0.10 & 6.01 \\
\hline
\end{tabular}

Behavioural cultural intelligence

$N=229$.

$\gamma$, completely standardised path coefficients; SE, standard error estimates.

$\dagger, t \geq|1.96|$ indicates significant parameter estimates.

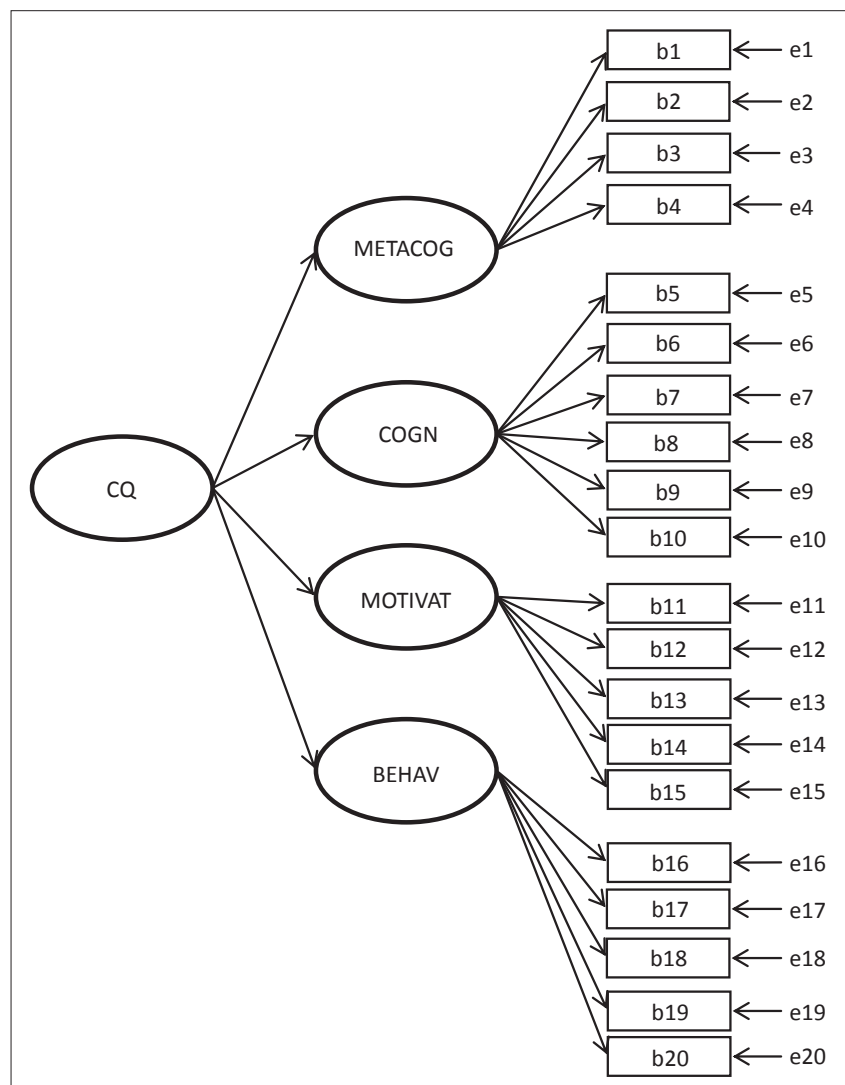

Source: Authors' own creation

$\mathrm{CQ}$, cultural intelligence; METACOG, Metacognitive cultural intelligence; COGN, Cognitive cultural intelligence; MOTIVAT, Motivational cultural intelligence; BEHAV, Behavioura cultural intelligence.

FIGURE 1: The cultural intelligence scale second-order confirmatory factor analysis path diagram indicating four first-order factors loading onto a single second-order cultural intelligence factor.

parameter in the model is freed and the model re-estimated (Jöreskog \& Sörbom, 1993). Large modification index values (> 6.6349 at a significance level of 0.01 ) are suggestive of parameters that would improve the fit of the model significantly $(p<0.01)$ when set free (Diamantopoulos \& Siguaw, 2000; Jöreskog \& Sörbom, 1993). The modification indices in the current study reflect the number of crossloadings between items and factors other than those they were designed to measure. For example, model fit would improve if items 5 and 19 loaded on the Metacognitive CQ dimension and item 4 loaded on the Behavioural CQ dimension. An inspection of the CQS items identified above indicates that, although the modification indices point to the direction of including the items as indicators of the latent variables that they are also loading on, it does not make theoretical sense to do so; furthermore, the modification indices are only marginally greater than the 6.6349 threshold, as these indices for items 4, 5 and 19 are 6.993; 7.273 and 7.580, respectively (Diamantopoulos \& Siguaw, 2000; Jöreskog \& Sörbom, 1993).

\section{Power assessment}

The power estimates for the tests of exact and close fit were determined via the Rweb (1.03) translation of the statistical analysis system (SAS) syntax provided by Preacher and Coffman (2006). Using this syntax, power values of 0.99 and 1 were derived for the respective tests of exact fit and close fit indicating that, under the conditions that characterised this study, approximately $100 \%$ of incorrect models would be rejected. This increases confidence in the model.

\section{Discriminant validity}

Discriminant validity was assessed using the method presented by Farrell (2010). This method involves comparing the average variance extracted (AVE) of each construct with the shared variance between constructs. The AVE indicates the average amount of variance in the indicator variables that is explained by the underlying latent variable that the indicator variables represent (Diamantopoulos \& Sigauw, 2000; Hair et al., 2010). Discriminant validity is supported if the AVE for each construct is greater than its shared variance with any other construct (Farrell, 2010). In this case, none of the shared variance estimates is greater than the AVE estimates for each of the constructs; therefore, discriminant validity is supported (see Table 4 ). The use of $95 \%$ confidence intervals utilising an Excel macro developed by Scientific Software International (Mels, 2010) also supported the inference that all four cultural intelligence latent variables demonstrate discriminant validity, as none of the confidence intervals approaches unity.

\section{Discussion}

The objective of this study was to assess the psychometric properties of the cultural intelligence scale (Ang et al., 2007) by testing the reliability and construct validity of the CQS on a South African sample. 


\section{Outline of the research results}

With the exception of the metacognitive cultural intelligence subscale, all the subscales had reliability coefficients above 0.80 . The relationships between the observed variables comprising the four latent variables of cultural intelligence were confirmed through first-order CFA. The results demonstrate that the CQS indicated sufficient construct validity. The second-order CFA confirmed that the four cultural intelligence dimensions contributed to an overall cultural intelligence construct. Thus, the four dimensions form one overall latent variable called cultural intelligence.

Based on the results of the present study on a South African sample it can be concluded that the cultural intelligence scale demonstrated good reliability, construct and discriminant validity. This outcome is consistent with the results reported in several other studies conducted in different countries, for instance Iran (Khodadady \& Ghahari, 2011), as well as on American and Singaporean samples (Ang et al., 2007).

\section{Practical implications}

This study has an important practical implication for crosscultural management in that it could help human resource professionals in their selection, training and development of a more culturally competent workforce, as well as using the CQS to evaluate the effectiveness of cultural diversity training programmes.

The study contributes to practice by confirming the psychometric properties of the CQS in a South African setting. The study also contributes to the legislative requirement that psychological instruments must be reliable and valid before they can be utilised in the South African context, as specified in the Employment Equity Act (No. 55 of 1998).

The findings of the present study suggest that the CQS was able to measure cultural intelligence reasonably well on a South African sample. The measure conformed, in this study, to the proposed first-order and second-order structures of cultural intelligence (Ang et al., 2007). Future studies should replicate the study on other South African population groups to further ascertain its psychometric properties.

\section{Limitations of the study and suggestions for future research}

It should be acknowledged that there is a need to replicate the study using a sample made up of employees in the public and private sectors to see whether similar results are obtained.

Secondly, flowing from the aforementioned weakness, the generalisability of the findings of the study might be limited by the fact that the sample that was used was mostly made up of young adults (under 30 years of age), was not adequately gender balanced and is not representative of the demographic profile of South Africans. Consequently, more research is needed on the structure of cultural intelligence in a more demographically balanced sample. Future studies should determine whether the measurement and structural models fit equally well when different cultural groups are compared; more work on the measurement equivalence or invariance of the CQS on a multicultural South African sample is required. In spite of these recommendations, however, extant findings indicate that the CQS may generalise relatively well across cultures (e.g. Ang et al., 2007; Khodadady \& Ghahari, 2011).

\section{Conclusion}

In the current study the psychometric evaluation of the CQS demonstrates good reliability and construct and discriminant validity. Generally, the results of this study are in line with studies conducted in other international contexts regarding the psychometric properties of the CQS. The study has also confirmed the second-order factor structure of cultural intelligence in which a higher-order cultural intelligence construct explains the variance of cultural intelligence in specific forms, as measured by the dimensions of the CQS.

The evidence provided in this study shows that the CQS may be an effective cultural intelligence measure that can facilitate empirical cultural intelligence research and practice. The CQS can be used to promote cultural intelligence as a means to enhance both job and academic performance through enhanced interaction and communication amongst individuals with different demographic backgrounds.

\section{Acknowledgements}

Thank you to Prof. Dirk J. Malan, Mrs Michelle Boonzaier, Mr Francois van der Bank, Mr Tendai Mariri, Mr Antony Otto and Ms Lindie van der Westhuizen for assistance with the data collection.

\section{Competing interests}

The authors declare that they have no financial or personal relationship(s) that may have inappropriately influenced them in writing this article.

\section{Authors' contributions}

B.M. (Stellenbosch University) was the project leader responsible for the data collection, statistical analysis and the conceptual write-up of the article, whilst A.S.E. (Stellenbosch University) also contributed to the write-up of the article.

\section{References}

Ang, S., Van Dyne, L., \& Koh, C. (2006). Personality correlates of the four-factor model of cultural intelligence. Group \& Organization Management, 31(1), 100-123. http://dx.doi.org/10.1177/1059601105275267

Ang, S., Van Dyne, L., Koh, C., Ng, K.Y., Templer, K.J., Tay, C., \& Chandrasekar, N.A. (2007). Cultural intelligence: Its measurement and effects on cultural judgment and decision making, cultural adaptation and task performance. Management and Organization Review, 3(3), 335-371. http://dx.doi.org/10.1111/j.17408784.2007.00082.x

Ang, S., Van Dyne, L., \& Tan, M.L. (2011). Cultural intelligence. In R.J. Sternberg, \& S.B. Kaufman (Eds.), The Cambridge handbook of intelligence (pp. 582-602). New York, NY: Cambridge University Press. http://dx.doi.org/10.1017/ CBO9780511977244.030

Brislin, R., Worthley, R., \& MacNab, B. (2006). Cultural intelligence. Group and Organization Management, 31, 40-55. http://dx.doi.org/10.1177/1059601105275262 
Chua, R.Y., \& Morris, M.W. (2009). Innovation communication in multicultural networks: Deficits in inter-cultural capability and affect-based trust as barriers to new idea sharing in inter-cultural relationships. Working paper. Boston, MA: Harvard Business School.

De Goede, J., \& Theron, C.C. (2010). An investigation into the internal structure of the learning potential construct as measured by the APIL-B test battery. Management Dynamics, 19(4), 30-55.

Deci, E., \& Ryan, R. (1985). The support of autonomy and control of behaviour Journal of Personality and Social Psychology, 53, 1024-1037. http://dx.doi. org/10.1037/0022-3514.53.6.1024

Diamantopoulos, A., \& Siguaw, J.A. (2000). Introducing LISREL. London, UK: Sage.

Du Toit, M., \& Du Toit, S.H.C. (2001). Interactive LISREL: User's guide. Lincolnwood, IL: Scientific Software International. PMCid:1729816.

Earley, P.C., \& Ang, S. (2003). Cultural intelligence. Individual interactions across cultures. Stanford, CA: Stanford University Press.

Elenkov, D., \& Manev, I. (2009). Senior expatriates leadership's effects on innovation and the role of cultural intelligence. Journal of World Business, 44(4), 357-369. and the role of cultural intelligence. Journal
$\mathrm{http}: / / \mathrm{dx}$.doi.org/10.1916/j.jwb.2008.11.001

Farrell, A.M. (2010). Insufficient discriminant validity: A comment on Bove, Pervan, Beatty and Shu. Business Research, 63, 324-327. http://dx.doi.org/10.1016/ j.jbusres.2009.05.003

Fehr, R., \& Kuo, E. (2008). The impact of cultural intelligence in multicultural socia networks. Paper presented at the 23rd annual conference of the Society for Industrial and Organisational Psychology (SIOP), San Francisco, CA, 10-12 April.

Groves, K.S., \& Feyerherm, A.E. (2011). Leader cultural intelligence in context. Group \& Organization Management, 36(5), 535-566. http://dx.doi. org/10.1177/1059601111415664

Gudykunst, W.B., Ting-Toomey, S., \& Chua, E. (1988). Culture and interpersonal communication. Newbury Park, CA: Sage.

Hair, J.F., Black, W.C., Babin, B.J., \& Anderson, R.E. (2010). Multivariate data analysis: A global perspective. (7th edn.). Upper Saddle River, NJ: Pearson.

Hofstede, G. (2001). Culture's consequences: Comparing values, behaviours, institutions, and organizations across nations. Thousand Oaks, CA: Sage.

Imai, L., \& Gelfand, M.J. (2010). The culturally intelligent negotiator: The impact of cultural intelligence (CQ) on negotiation sequences and outcomes. Organizationa Behaviour and Human Decision Processes, 112, 83-98. http://dx.doi. org/10.1016/j.obhdp.2010.02.001

Ismail, A.M., Reza, R., \& Mahdi, S. (2012). Analysis of the relationship between cultural intelligence and transformational leadership: The case of managers at the trade office. International Journal of Business and Social Science, 3(14), 252-261.

Jöreskog, K.G., \& Sörbom, D. (1993). LISREL 8: Structural equation modelling with the SIMPLIS command language. United States of America: Scientific Software International, Inc

Jöreskog, K.G., \& Sörbom, D. (1996). LISREL 8: User's reference guide. Chicago, IL: Scientific Software International.

Kamps, J.M., \& Engelbrecht, A.S. (2011). The influence of emotional intelligence on diversity complexity cognition and the attitude towards diversity. South African Journal of Business Management, 42(3), 37-48.

Khodadady, E., \& Ghahari, S. (2011). Validation of the Persian cultural intelligence scale and exploring its relationship with gender, education, travelling abroad and place of living. Global Journal of Human Social Sciences, 11(7), 65-75.
Mahembe, B., Engelbrecht, A.S., \& De Kock, F.S. (2013). A confirmatory factor analytic study of a self-leadership measure in South Africa. SA Journal of Human Resource Management, 11(1), 10 pages. http://dx.doi.org/10.4102/sajhrm.v11i1.520

Mayer, J.D., \& Salovey, P. (1993). The intelligence of emotional intelligence. Intelligence, 17, 433-442.

Mels, G. (2003). A workshop on structural equation modelling with LISREL 8.54 for Windows. Port Elizabeth, South Africa: University of Port Elizabeth.

Mels, G. (2010). Structural equation modelling with LISREL 9 for Windows. Chicago, IL: Scientific Software International.

Ng, K.Y., Van Dyne, L., \& Ang, S. (2012). Cultural intelligence: A review, reflections, and recommendations for future research. In A.M. Ryan, F.T.L. Leong, \& F.L. Oswald
(Eds.), Conducting multinational research: Applying organizational psychology in the workplace (pp. 29-58). Washington, DC: American Psychological Association.

Nunnally, J.C. (1978). Psychometric theory. New York, NY: McGraw-Hill.

Preacher, K.J., \& Coffman, D.L. (2006). Computing power and minimum sample size for RMSEA [Computer software]. Available from http://quantpsy.org/

Rockstuhl, T., Ang, S., Ng, K.Y., Van Dyne, L., \& Lievens, F. (2009). Cultural intelligence and leadership emergence in multicultural teams. Paper presented at the 69th annual meeting of the Academy of Management, Chicago, IL, 7-11 August.

Schmidt, F.L., \& Hunter, J.E. (2000). Select on intelligence. In E.A. Locke (Ed.), The Blackwell handbook of organizational principles (pp. 3-14). Oxford, UK: Blackwell.

SPSS [Computer software] (2011). Armonk, NY: IBM Corp.

Sternberg, R.J., \& Detterman, D. (1986). What is intelligence: Contemporary viewpoints on its nature and definition. Norwood, NJ: Ablex.

Sternberg, R.J., \& Wagner, R.J. (2000). Practical intelligence. In R.J. Sternberg (Ed.), Handbook of intelligence (pp. 380-395). New York, NY: Cambridge University Press. http://dx.doi.org/10.1017/CBO9780511807947

Tabachnick, B.G., \& Fidell, L.S. (2001). Using multivariate statistics. (4th edn.). Needham Heights, MA: Allyn \& Bacon.

Tay, C., Rossi, A.M., \& Westman, M. (2010). International business travellers: Inter-role conflicts and moderating effects on emotional exhaustion. Paper presented at the annual meeting of the Academy of Management, Montreal, Canada, 6-10 August.

Thorndike, R., \& Stein, S. (1937). An evaluation of the attempts to measure social intelligence. Psychological Bulletin, 34, 275-285. http://dx.doi.org/10.1037/ h0053850

Triandis, H.C. (2006). Cultural intelligence in organizations. Group and Organization Management, 31, 154-173. http://dx.doi.org/10.1177/1059601105275253

United Nations High Commissioner for Refugees (UNHCR) (2010). 2010 UNHCR country operations profile - South Africa. Retrieved May 05, 2013, from http:// www.unhcr.org/cgi-bin/texis/vtx/page?page=49e485aa6

Van Dyne, L., \& Ang, S. (2005). Personality and cultural intelligence: Examining discriminant validity and interrelationships. Paper presented at the American Psychological Association, Washington, DC, August.

Williams, L.J., Vandenberg, R.J., \& Edwards, J.R. (2009). Structural equation modeling in management research: A guide for improved analysis. The Academy of Management Annals, 3(1), 543-604. http://dx.doi.org/10.1080/19416520903065683 